\title{
POLÍTICA NA RUA: SUBJETIVAÇÃO, RESISTÊNCIA E OCUPAÇÃO DOS ESPAÇOS PÚBLICOS
}

\author{
POLÍTICA EN LA CALLE: SUBJETIVACIÓN, RESISTENCIA \\ Y OCUPACIÓN DE LOS ESPACIOS PUBLICOS
POLITICS IN THE STREET: SUBJECTIVATION, RESISTENCE AND OCCUPATION OF PUBLIC SPACES

\author{
Jaqueline Tittoni ${ }^{1}$ e Lúcia Karam Tietboehl ${ }^{1}$
}

${ }^{1}$ Universidade Federal do Rio Grande do Sul, Porto Alegre/RS, Brasil

RESUMO: Este artigo compõe uma dissertação de Mestrado desenvolvida junto aos movimentos sociais que utilizam a ocupação dos espaços públicos como estratégia de resistência, na cidade de Porto Alegre, nos anos de 2013 a 2015. Através do referente metodológico da cartografia, seu objetivo foi mapear formas de subjetivação produzidas nestes processos, articulando as noções de ocupação como estratégia dos movimentos sociais e as formas de ocupação de si, presentes na discussão sobre a ética do cuidado de si no pensamento foucaultiano. Para tanto, faz uma breve discussão sobre as singularidades destes movimentos sociais, partindo para a discussão sobre a noção de "ocupação" em nível teórico, finalizando com algumas aberturas que a discussão propôs e com a afirmação de um lugar possível que articule a pesquisa e a militância nos movimentos sociais como uma problematização ética.

PALAVRAS CHAVE: ocupação do espaço público; ética do cuidado de si; modos de subjetivação; movimentos sociais.

RESUMEN: El siguiente artículo se basa en una disertación de maestrado, desenvolvida junto a los movimientos sociales que ocupan espacios públicos como estrategia de resistencia, en la ciudad de Porto Alegre, entre los 2013 y 2015. Por los referenciales metodológicos de la cartografia, el objetivo de este trabajo fué mapear modos de subjetivación producidas en estos procesos, articulando las nociones de ocupación como estrategia de los movimientos sociales y las formas de ocupación de si, presentes en la discusión sobre la ética del cuidado de sí del pensamiento foucaultiano. Por lo tanto, realiza una breve discusión sobre las singularidades de estos movimientos sociales, continuando con la discusión sobre la noción de "ocupación" a nivel teórico, finalizando con algunas aberturas que la discusión propone y la afirmación de un lugar posible que articule la investigación y la militancia de los movimientos sociales como una problematización ética. PALABRAS CLAVE: ocupación del espacio público; ética del cuidado de sí; modos de subjetivación; movimientos sociales.

ABSTRACT: This article is part of a thesis for a master degree developed from and together with the social movements that used the occupation of public spaces as a resistance strategy in the city of Porto Alegre, between the years of 2013 and 2015. Its purpose is to use cartography as a methodological reference in the mapping of the subjectivation forms produced in this process, relating the notion of occupation, as an strategy of the social movements, to the ways of occupying the self: present terms in the foucaultian thought (more specifically, in the issue of the care of the self). The text starts with a brief discussion on the sungularity of these social movements, passing on to the theoretical debate on the concept of "occupation", and ends up with some openings brought by this discussion. Also, there is an analysis of the possible ways to relate the activities of research and militance in the social movements, considering its ethical implications.

KEYWORDS: occupation of public spaces; ethics of the care of the self; subjectivation ways; social movements. 


\section{Introdução}

Este artigo tem como referência uma dissertação de Mestrado que acompanhou os coletivos que se organizavam pela ocupação do espaço público na cidade de Porto Alegre entre os anos de 2013 e 2015 , buscando mapear formas de subjetivação envolvidas nesta nova modalidade de articulação política. Em termos mais amplos, buscamos discutir a experiência urbana e os modos de subjetivação e resistência que compõem as múltiplas formas de viver na cidade, de habitar e percorrer seu território e acessar os espaços e bens que ela produz. Buscamos identificar que prescrições se relacionam aos modos de existência urbanos, colocando em análise as possibilidades de transgressão destes regramentos e de afirmação das diferenças. Apostamos, portanto, que os movimentos de ocupação do espaço público podem oferecer importantes pistas sobre tais questões, por trazerem de maneira pulsante, também, a discussão sobre o direito à cidade.

Tomamos como ponto de partida a contextualização dos movimentos de ocupação dos espaços públicos e suas condições de possibilidade - sobretudo na cidade de Porto Alegre - para apresentar duas linhas que, ao enredarem-se, compõem os modos de politizar-se colocados em análise: a linha da ocupação do público e os modos de ocupação de si. A partir de 201 1, novas formas de insurgência tomaram as ruas em diferentes países e continentes. Guardadas as diferenças locais que marcaram estes encontros populares, tem-se a estratégia de ocupação do espaço público como linha que transversaliza essas expressões e que, nesses moldes, toma visibilidade e importância diferenciadas, configurando-se como uma expressão própria desse tempo. Assim, a noção de ocupação atravessa esta discussão, tanto a nível teórico, quanto do ponto de vista da experiência do pesquisar e de participar de tais movimentos.

A noção de "ética do cuidado de si”, proposta por Michel Foucault, é um interessante articulador para pensar sobre as questões éticas e políticas implicadas em nossa reflexão, pois, no campo dos movimentos sociais e da atitude crítica coletiva, torna-se pertinente a problematização do poder, da liberdade e da luta como estratégia para uma análise crítica dos movimentos sociais e dos modos de subjetivação produzidos neles.

Esta articulação entre modos de ocupação está relacionada, também, ao fato de que nossa experiência do pesquisar levou em consideração as tensões entre os lugares de militante e de pesquisadora, assim como suas implicações nas reflexões éticas que colocam em jogo as analogias possíveis entre as práticas militantes e o pesquisar. Ao tensionar estas duas posições, busca-se ampliar a problematização do presente, como um ato de presença e como um efeito de presença, tal qual o proposto por Foucault (2012). Neste caso, a problematização do presente se articula como problematização, também, da presença, como fator fundamental nas práticas éticas e reflexivas do pesquisar. Ao provocar estas tensões, estranhar ambas as posições torna-se, ao mesmo tempo, necessidade e potência. Podendo criar condições de emergência de outros pesquisares e de diversos modos de militância.

Com relação à metodologia: a cartografia, conforme proposta por Deleuze e Guattari (1995), é o referente metodológico mais importante deste estudo e se propõe a acompanhar os processos, mais do que a descrever objetos (Barros \& Kastrup, 2012). A partir da crítica aos ideais de neutralidade e objetividade que, segundo a ciência moderna, seriam o único caminho para o conhecimento científico, o referencial cartográfico dá espaço aos afetos daquele que pesquisa, como agenciamento dos modos de conhecer. Esta foi uma escolha potente frente à necessidade de pesquisar sobre processos que formam a própria 
experiência na cidade e na militância. Assim, de acordo com o que se espera de uma pesquisa cartográfica, o objeto de pesquisa não são os movimentos de ocupação, mas os percursos realizados junto a estes coletivos e a forma como o pesquisar e o campo foram sendo compostos mutuamente.

O diário de pesquisa (Hess \& Weigand, 2006) foi a principal referência para a análise deste percurso. Além do diário individual, foi utilizado um diário coletivo, conforme proposto por Lazzarotto (2009), que se compôs através de uma lista de e-mails da qual participam os membros de um coletivo militante específico, para realizar combinações de agenda, marcar reuniões e trocar informações objetivas. Além dessas funções, tal espaço virtual foi potente ao ser território de análise da própria prática militante. A ferramenta da Análise de implicação (Baremblitt, 1996) também foi importante no direcionamento de nossa relação com os processos pesquisados.

Com relação às ferramentas teóricas utilizadas, nossa principal referência é o pensamento foucaultiano. Ao propor uma filosofia ligada às formas de vida, Michel Foucault afirma que a função do pensamento filosófico caminha junto à atitude de crítica e à possibilidade de refletir sobre o que se vive. Dessa forma, o autor define a filosofia como um estilo de vida e não como habilidade argumentativa com vistas à descoberta da "verdade". Assim, mais do que fornecer um corpo conceitual, o pensamento foucaultiano ofereceu uma orientação ética para o trabalho de pesquisa, deu forma a um pesquisar, auxiliando também na construção das perguntas sobre os processos a conhecer.

As noções de ética, poder e práticas de liberdade propostas pelo autor são importantes articuladores teóricos da pesquisa. Sob este referencial, as práticas reflexivas permitem um fazer ético e são capazes de dar potência às práticas de liberdade. As atitudes éticas, nessa construção filosófica, não são determinadas por ordenamentos morais preestabelecidos, pois se relacionam, de preferência, com um caráter de criação e de invenção, relativizando modelos e prescrições.

Esta exposição inicia com uma breve discussão sobre os movimentos sociais que utilizam a ocupação como estratégia de luta na cidade de Porto Alegre, partindo para uma discussão sobre a noção de "ocupação" como ferramenta teórica e finalizando com algumas aberturas que a discussão propôs e com a afirmação de um lugar possível que articule a pesquisa e a militância nos movimentos sociais como uma problematização ética.

\section{Os movimentos sociais e a ocupação dos espaços públicos}

Para a construção desta análise, não se pode interpretar a expressão "ocupação do espaço público" como algo dado, mas como uma atitude que deve ser entendida em suas especificidades. Quais as marcas desta forma de resistência e em que ela se diferencia de outras maneiras de ocupação? Existem diferenças entre ocupar a rua e ocupar bens imóveis privados? Estas perguntas podem oferecer as primeiras pistas para pensarmos sobre como esta estratégia se constitui.

O ato de ocupar, como estratégia política, não é uma atitude que se inaugurou nos últimos anos. Seja no ambiente rural ou urbano, a ocupação como resistência surge em diferentes situações, tomando espaços que estão abandonados e produzindo seu uso comum. A situação de abandono legitima a expropriação dos espaços privados, pois de acordo com 
o inciso XXIII do artigo 5 da Constituição Federal (Constituição Federativa, 1988), qualquer propriedade, para se legitimar como tal, deve cumprir função social. Não existe, no entanto, um controle estatal efetivo neste sentido e, mesmo frente à falta de garantia do direito à moradia enfrentado por diversos grupos sociais, é comum que o Estado realize ações de despejo em áreas ocupadas, legitimando o não cumprimento do artigo constitucional. A prática de ocupação destes bens, portanto, desnaturaliza a lógica da propriedade privada - ainda mais reforçada no pensamento liberal e avalizada pelas gestões estatais que afirma a sobreposição da propriedade ao uso social e comum dos bens privados.

No Brasil, o Movimento dos Trabalhadores Rurais Sem Terra é um importante movimento social que se organizou em torno da ocupação como principal estratégia política. O movimento se forma a partir de uma identidade coletiva, desenvolvida sobre a figura do "sem-terra", que pressupõe uma consciência comum da situação de exclusão social, derivada da falta de acesso à terra, aos meios de produção e a condições dignas de existência (Varella, 1998). Quando famílias de camponeses se instalam em latifúndios improdutivos, realizam uma forte crítica à desigualdade de acesso à terra e à especulação fundiária que leva ao êxodo rural e restringe as condições da população do campo. Além deste movimento, próprio do meio rural, crescem também as ocupações em grandes cidades, desempenhadas por grupos populares, ligados a movimentos sociais da luta por moradia, que exigem o direito ao espaço para morar, tencionando as políticas de urbanização que elitizam os grandes centros e impelem as pessoas de baixa renda a se deslocarem para as periferias cada vez mais distantes. Além destes, cresce o número de ocupações realizadas por coletivos ligados à ideologia anarquista e a referências culturais relacionadas ao movimento hippie e punk, que além da crítica à propriedade privada questionam ideais capitalistas de consumo desenfreado (Gallo, 2008).

A partir de 2011, no entanto, adquirem visibilidade ocupações que se diferenciam destas, pela natureza dos bens a que se dirigem. As ocupações do que é público (e supostamente de uso comum), como estratégia de luta destes novos grupos urbanos, são pontuais (ou seja, não pretendem ser permanentes como nos bens privados) e se dão através do uso de ruas e praças como espaços de encontro e articulação. Quando a atitude de estar na rua passa a ter características de ocupação e as pessoas que habitam a cidade exigem acesso ao que supostamente já lhe estaria garantido por direito, ascendem novos estranhamentos: o que significa a necessidade de ocupar o que é público? Que tipo de restrição - assim como na ocupação de bens privados - legitima o uso desta estratégia? O que significa a necessidade de pontuar o direito de acesso à rua e ao que é público, já que este acesso estaria supostamente garantido?

No ano de 2011, diferentes cidades ao redor do mundo foram palco de expressões insurgentes que guardavam muitos pontos em comum, apesar de suas diferenças locais. A linha que transversaliza os acontecimentos em questão - tanto no Brasil como nos movimentos internacionais - é a linha da ocupação do espaço público, em especial das ruas e praças, como estratégia popular de luta e resistência. Em termos gerais, a literatura ainda recente sobre o assunto coloca a crise financeira de 2008 como condição de possibilidade para essas expressões políticas (Joffe, 2011; Harvey, 2012; Zizek, 2012). Para estes autores, a crítica às desigualdades econômicas compõe o centro das reivindicações presentes nos gritos ouvidos nas ruas. $\mathrm{O}$ contexto de globalização em que vivemos desde os anos 90 e a crise financeira que atingiu diversos países não só da periferia, mas do centro - o núcleo orgânico do capitalismo - (Alves, 2012), produziram um novo comportamento político por parte das classes médias. 
Assim, um processo disparado na Tunísia no final de 2010 dá origem à Primavera Árabe, que rapidamente atinge o ocidente, com movimentos de ocupação da rua em diversas cidades da Europa, da América do Norte e da América Latina. O "contágio" que se alastrou pelos diferentes continentes, produzindo formas de resistência semelhantes - apesar das especificidades de cada lugar - aponta para certa paridade presente nas estratégias utilizadas para o fortalecimento do capital, que também parecem repetir-se nesses diferentes locais, ainda que com algumas variações. Ao olhar para essas novas formas de resistência, Safatle (2012) afirma que esse é um exemplo de momento histórico em que as ideias, ao circularem, transpõem as limitações do espaço e encontram seu próprio tempo. A força que desencadeia esta circulação pode sinalizar que os pensamentos estavam, de alguma forma, presentes em diferentes lugares e esperando para tornarem-se visíveis e enunciáveis, produzindo assim novas práticas.

Ainda que tais expressões tenham como ponto central as críticas ao capitalismo como modelo econômico, os diferentes movimentos de ocupação do espaço público apontam para um pensamento político diferenciado que articula as desejadas mudanças sociais, políticas e econômicas às mudanças culturais, ou seja, às mudanças que implicam na criação de novos modos de viver. Dessa forma, as relações sociais são consideradas como imanentes - de acordo com a noção de imanência proposta por Deleuze e Guattari (1992) -, ou seja: transformar o que compartilhamos socialmente passa diretamente pela experiência dos sujeitos que compõem os processos vividos na cidade. Este talvez seja um interessante ponto de ruptura com relação ao pensamento político de alguns setores da esquerda, caracterizados pela forma transcendente como por vezes concebem as relações sociais e as possibilidades de transformá-las, muitas estipuladas a priori da experiência.

Ao focarmos nos movimentos da cidade de Porto Alegre, identifica-se algumas particularidades: a intensificação das parcerias público-privadas, o processo de repressão à vida boêmia, o surgimento e o fortalecimento de coletivos que exigem novas políticas de mobilidade urbana (em especial com o ato em repúdio ao atropelamento de ciclistas em massa, ocorrido em fevereiro de 2011) e as medidas adotadas para receber a Copa da FIFA de 2014. Estas últimas dizem respeito ao redesenho do espaço público, ao gasto de verba pública para a implementação de grandes obras que não respeitam o plano diretor da cidade, à remoção de famílias de áreas populares e às ameaças contra a soberania do país frente as exigências da organização internacional que trouxe o evento esportivo ao Brasil.

Em Porto Alegre, a situação de restrição de uso e acesso ao espaço público ou estatal - que os movimentos de ocupação vêm combater - se constitui a partir de jogos de verdade que se constroem e modificam com o passar do tempo. Nestes processos ascendem novas premissas, que adquirem um caráter de legitimidade e passam a organizar as diferentes instituições que compõem a cidade. Nestas novas legitimidades, a lógica das privatizações torna-se algo "natural", recorrente, pouco combatido.

Relacionada à constituição de uma "ética do privado", a pouca resistência encontrada por este tipo de processo parece denunciar que a maior parte dos habitantes da cidade não se sentem apropriados dos espaços nem suficientemente envolvidos com eles para esboçarem reações que possam combater a restrição de acesso ao que é supostamente de todos. As contradições do capitalismo, expressas nas diversas formas de segregação vividas na cidade, demarcam um intenso processo de privatização do espaço urbano.

Com relação às especificidades vividas aqui, a desapropriação destes espaços por parte da população parece operar a partir da ideia de que "o espaço público é de ninguém”. 
Quais as condições de possibilidade para o fortalecimento desta ideia e quais desdobramentos e posturas ela produz? Talvez uma pista frente a esta discussão possa estar na transformação de espaços da rua em locais de passagem, meras vias para se chegar de um ponto a outro. Isso acontece quando lugares que teriam vocação para se constituírem como espaço de permanecer - debatendo sobre o que se experiencia no social ou simplesmente confraternizando e deixando passar o tempo - passam a ser vistos como locais sobre os quais circulamos sem ter o hábito de parar (Mizoguchi, 2009).

A experiência nos movimentos sociais mostra que isso acontece em praticamente todas as calçadas, alguns parques e a maioria das praças da cidade. De forma persistente - mas muitas vezes sutil - insiste-se em uma desvalorização do público como espaço de encontro de todos e para todos os que habitam a cidade. Este também é um reflexo da relação dos sujeitos com o tempo e o trabalho, permeada por discursos e jogos de verdade que afirmam que os momentos em que não se produz são momentos de ócio, portanto inúteis armadilhas a serem evitadas. Assim, configura-se um cenário em que as calçadas e as praças são apenas usadas como via, como meio para se chegar de um lugar a outro, ao mesmo tempo caminho e obstáculo, já que o que realmente "tem importância" - gera frutos e compõe as práticas consideradas "produtivas" - não deve acontecer ali. Ao passo em que aumenta o valor do que é privado - sendo esta instância o suporte para um número cada vez maior de práticas - fortalece-se a sensação de que o que é público já não nos pertence, transformando-o em um assunto com o qual não nos envolvemos. Dessa forma, o uso que os novos movimentos fazem da rua, como espaço de permanecer e como palco para articulações políticas entre diferentes sujeitos também produz função no combate à ideia de que o que é público é “de ninguém”.

Em Porto Alegre, desde 2011 existe uma manifestação que questiona a ideia de que é preciso pagar para se ter momentos de encontro e lazer. O Largo Vivo - nome dado a encontros que acontecem no Largo Glênio Peres, situado em frente ao Mercado Público - surgiu para contestar um decreto municipal, de 2011, que transformou este largo - às noites e durante os finais de semana - em um estacionamento para carros. A ideia que motiva o nome dos encontros é a de que um largo, bem como qualquer espaço da cidade, apenas pode ser "vivo" quando as pessoas podem usá-lo como um lugar para desenvolver a vida em coletivo. Quando uma parte da população passa a utilizar a rua como espaço de diversão, o que costumava até então acontecer em âmbitos privados, se rompe a ideia do lugar de medo, de "todos contra todos", transformando-a em um ambiente para compartilhar amizades, amores e outros afetos.

Por outro lado, a visão da rua como um espaço de medo e insegurança é reforçada de inúmeras formas, sendo que os meios de comunicação de massa têm uma importante função neste processo com reportagens e programas de cunho sensacionalista que valorizam situações de violência (Barros, 2003) vividas na rua, transformando-as no argumento de que, justamente por ser o lugar onde é possível encontrar diferentes, a rua é perigosa. Caldeira (1997) afirma que as crescentes medidas de segurança e vigilância - e, portanto, o aumento da segregação - são legitimadas pelo medo do crime, expresso através de falas que produzem e fazem circular estereótipos. Nestas formações estereotipadas, compreende-se os outros grupos sociais (ou apenas "os outros") como um perigo em potencial que precisa ser evitado.

Estas concepções também impulsionam a visão da rua como um espaço de ninguém, pois quando a ideia de estar em um lugar produz medo, pode-se arbitrariamente deixar de usá-lo. 
Quando se percebe a potência da rua na produção da vida e de laços que nos aproximam, pode-se ter com ela novas experiências, que permitem relativizar a falta da sensação de segurança, para assim cuidarmos e nos responsabilizarmos por ela, defendendo o direito de usá-la de maneira plural e não homogênea.

Lefebvre (2000), afirma que os espaços urbanos estão sempre sendo construídos como um conjunto de relações sociais e que tais relações podem assumir um sentido de produto ou obra. Estes sentidos se relacionam com as características produzidas pelos valores de uso e os valores de troca que os espaços podem ter. Quando um espaço estimula valores de uso como o encontro e a convergência entre diferentes, produz as condições para o fortalecimento de uma obra criativa e, de acordo com Konzen, "revela-se a si mesmo como obra, na acepção forte de obra de arte” (2010, p. 68). Por outro lado, um espaço pode ser considerado um produto quando as dinâmicas que o envolvem fundam-se em valores de troca, transformando-o em mercadoria e fonte de acúmulo de capital.

Nestes casos os valores de uso podem ser trocados por dinheiro, como na ideia em que é preciso pagar para se divertir, ou para encontrar-se. Além dos espaços, as relações sociais também podem adquirir um caráter de mercadoria quando se naturaliza a ideia de que é preciso pagar para se ter prazerosos encontros entre amigos.

Para Lefebvre, a diferenciação entre um espaço que é obra e outro que é produto se dá pelo balanço das qualidades que eles podem apresentar. É possível que diferentes valores de uso e de troca determinem um mesmo lugar, por isso é um balanço destas qualidades que irá dizer em qual situação se encontra. Nos modos capitalistas da produção dos espaços, é comum a sobreposição dos valores de troca sobre os de uso.

A luta pelo direito à cidade, portanto, trata de tornar possível a acepção de espaços que sejam obras de arte, à medida em que podem ser compostos por cores, sons e sabores vibrantes e diferentes. Homogeneidade e pasteurização são ideias que não combinam com a acepção do espaço ou da vida como obra de arte. Manifestações como o Largo Vivo e outras, que ao ocupar insistem no fortalecimento dos valores de uso da cidade, vem tomar parte na disputa pela sua transformação em obra, plural e rica na diversidade.

Existem outros processos, de responsabilidade da gestão estatal, que também podem construir a ideia de que o espaço público é “de ninguém”. Muitos locais são deixados em situação de abandono ou com o acesso restrito por diferentes motivos: seja pela construção de muros e grades que bloqueiam fisicamente o acesso a esses bens, seja pela sensação de insegurança ou mesmo pela impossibilidade de desenvolvimento de atividades nestes locais. Com a falta de incentivo ao uso, acontece uma desapropriação dos espaços e a população não vê aquele local como seu, do qual tem o direito de usufruir e a responsabilidade de cuidar - inclusive por um cuidado que poderia se dar através da defesa dos direitos de uso que lhe cabe.

Passam-se os anos, surgem então as propostas de privatização, avalizadas pelo poder público, extremamente ativo na transformação dos espaços (Narciso, 2009). Por vezes tais propostas nem se tornam visíveis para grande parte da população, que já não utiliza os bens em questão, cujo acesso está restrito há tempos. Dessa forma, os processos de transformação dos bens públicos em fonte de capital privado encontram menor resistência popular, também pelo fato de a população não se perceber como habitante destes locais.

Estas situações, inclusive, constroem alguns argumentos falhos que valorizam as privatizações, como aquele que sugere que estes espaços serão tornados "frequentáveis", mas que formam um discurso incompleto ao ignorarem as contrapartidas a serem recebidas pelas empresas responsáveis pelas obras de reforma ou "revitalização", e por vezes até 
mesmo pela gestão dos bens. Tais argumentos negam, também, a responsabilidade do poder estatal em garantir o acesso ao que é público e de manter sua autonomia com relação ao capital privado. Quando esta responsabilidade se perde, cria-se uma estrutura de estado que, inevitavelmente, acaba por beneficiar porções específicas da população, face a outras.

Na cidade de Porto Alegre, estes processos se desenharam em alguns locais de bastante importância social, cultural e simbólica. Alguns dos exemplos emblemáticos são o Auditório Araújo Vianna (entregue pela prefeitura à iniciativa privada em 2007) e a privatização do Cais Mauá, na região central do antigo porto fluvial da cidade. Ambos os espaços, sucateados pela gestão estatal, foram entregues à iniciativa privada sem que se realizasse debates efetivos com a população que, apartada de seus espaços, também não apresentou grande interesse em defendê-los.

As chamadas "revitalizações” também são uma prática cada vez mais comum e afirmam-se sobre o discurso de que é preciso "devolver" a vida a determinados locais, situados principalmente nas regiões centrais da cidade, com importância histórica e simbólica. Muitos dos espaços para os quais se dirigem tais propostas são locais de grande circulação das camadas populares, utilizados para práticas de lazer ou trabalho, quase sempre informal.

A partir disso, surge mais um estranhamento: por que se fala em devolver vida a lugares que estão cheios dela? Uma análise crítica, que relacione estes discursos aos usos feitos dos locais, permite concluir que o que está em questão são processos de gentrificação, não de revitalização. Gentrificação é o nome que se dá à busca por "qualificar" o público frequentador dos espaços (Alves, 2011) - sendo, nestes casos, o poder aquisitivo considerado como sinônimo de qualidade. Um exemplo disso é o projeto de "revitalização" da orla do Rio Guaíba, principalmente no trecho próximo à Usina do Gasômetro. Este ponto - situado também na região central da cidade - talvez seja, no centro, o espaço aberto em que mais circulam pessoas vindas da periferia durante os finais de semana na capital. Estes sujeitos utilizam a orla como ponto de lazer e para o contato com o rio, já que muitas vezes vivem em regiões distantes. Além disso, desempenham, ali, atividades de trabalho informais e o comércio popular, como a venda de bebidas, alimentos e artesanato. Mesmo que a vida neste espaço seja pulsante e salte aos olhos, expressa modos de viver que diferem daqueles da elite. O poder público não deixa de nomear como "revitalização" a série de reformas às quais pretende submeter o espaço.

A privatização e a gentrificação, ao transformarem o que é público em espaço centrado no consumo, atuam também para transformar-nos em meros consumidores. Devido à violência com que certos modelos pressionam para reordenar os espaços e impor certas formas estéticas, perde-se a noção de uma história diversificada e compartilhada da cidade, que acolha os diferentes sujeitos e suas formas de experimentar a vida no meio urbano. Estes processos atuam na produção de sujeitos "ninguéns", ao buscarem silenciar aquilo que marca tais pessoas de maneira singular, em nome da homogeneização. Aliada à sensação de que o espaço público "é de ninguém”, desponta um afeto ligado aos movimentos de ocupação que diz respeito a um “cansaço de ser ninguém”. Ser ninguém, nesta situação, se refere a jogos de verdade que reduzem os sujeitos da cidade à condição de meros consumidores. Frente à transformação dos espaços e à mercantilização dos modos de viver, a atitude de ocupar a rua, ao pautar a necessidade de invenção de novos comuns, parece sinalizar este cansaço desses sujeitos colocados em "posições ninguéns”.

É possível relacionar este cansaço com a fratura das identidades (Hardt \& Negri, 2004) e a busca por "anonimato", que produz uma marca significativa no pensamento político desta 
década. O que o anonimato pode significar neste cenário? Ser anônimo não é sinônimo de ser ninguém, mas, neste caso, parece apontar para o contrário. Em primeiro lugar, produzir uma vida que se pretende anônima parece sinalizar a falta da necessidade de ter uma identidade ou até uma busca ativa pelo não enquadramento aos critérios identitários. A busca por anonimato pode estar relacionada ao desejo de criar uma vida que possa ser incompreensível para o olhar capturante do mercado, como postura de resistência às lógicas operadoras de desigualdades e aplainadoras das diferenças. Se trata de um aparente paradoxo: frente a olhares que estão à caça de novas subjetividades a serem convertidas em fonte de capital, só o que pode ser aparentemente "vazio" pode estar cheio de pluralidades.

$\mathrm{O}$ anonimato também se relaciona com a falta de hierarquia pretendida pelos movimentos de ocupação do espaço público. Quando uma multidão pode se reunir em torno de reivindicações e desejos sem a necessidade de uma figura que as centralize, parece que se estabelece uma formação que aponta para o que Hardt e Negri (2004) chamam de comum. A expressão "não me representa" é repetida em diferentes movimentos de ocupação da rua e esta contraposição à noção de representação também é dirigida aos representantes políticos, aos estereótipos, à mídia, aos ideais de sucesso e consumo, entre outros.

Como dito anteriormente, parece que estas práticas - de abandono, privatização e gentrificação - ao mesmo tempo que sustentam a ideia de que o que é público "é de ninguém”, também fomentam a noção de sujeitos que se reconhecem no âmbito privado. Este afastamento entre a população e as coisas da cidade - espaços e decisões - é ativo na produção de sujeitos que "preferem" os espaços privados, aos públicos. Com isso vê-se reforçada uma ética do privado como instância que pode poupar do contato com os diferentes, produzindo a desejada sensação de segurança frente à suposta barbárie de um mundo em que as diferenças são tantas que fogem ao controle. Frente a isso, os movimentos de ocupação do espaço público apontam para uma ética do comum (tensionando a ética do privado), onde a diversidade pode ter expressão e criar espaços não "de ninguém”, mas que se pretendem "de todos". Segundo Castells (2013), ocupar a rua seria criar um novo espaço público, que se torne visível na vida social.

Tomamos a noção de comum proposta por Hardt e Negri (2004), que denomina aquilo que é compartilhado e desvinculado tanto do privado quanto do público. Isso significa dizer também que, ao ocuparem, esses sujeitos não valorizam o Estado - da forma como ele se estrutura - como uma confiável instância reguladora das relações. Esta noção é interessante pois parece pontuar uma diferença importante com relação aos movimentos e partidos políticos que têm, como importante objetivo, o acesso a cargos políticos. Neste caso, os novos coletivos parecem não defender o fortalecimento da instância estatal como solução política que poderia produzir proteção frente às desigualdades; ao contrário, afirmam que os movimentos sociais possam exercer posturas cada vez mais autônomas, tanto com relação à iniciativa privada, mas também com relação ao Estado, que é cada vez menos considerado como um lugar de poder a ser "conquistado" através dos processos eleitorais.

Para caracterizar a noção de comum, Hardt e Negri (2004) afirmam que ela remete à ideia de "comunicação" e não de "comunidade". Apesar da polifonia relacionada a tais conceitos, neste trabalho tomaremos como a referência a produção dos referidos autores, que se propõem a pensar os novos movimentos sociais como produção de uma multidão. Na multidão (ao contrário do povo, que é uno) cabem a singularidade e a diversidade, agregadas não por uma identidade compartilhada, mas por empatia e objetivos comuns. Diante disso, caracterizam de modo oposto a comunidade, que seria uma unidade na qual 
a singularidade dos sujeitos se vê dissolvida: na comunidade todos são, de alguma forma, "iguais". No comum, pelo contrário, as formações singulares existem em comunicação aberta com outras. Assim, esta seria uma construção possível a partir do reconhecimento do outro, o que produz e se produz do encontro entre singulares diferentes.

Ela, a multidão, só existe como tal enquanto for luta: não se trata apenas do encontro ou da soma entre diferentes; a multidão acontece quando algo "a mais" acontece entre estes sujeitos, quando o encontro destas diferenças pode produzir algo novo, que nenhuma das partes era até então e que nem poderiam ser se não experienciassem o encontro. Assim, é possível afirmar que sujeitos singulares, unidos na diversidade e em torno de um comum, têm grande potência para "serem luta" e para transformarem-se. Dessa forma, ao denunciarem a privatização do público sem enaltecer o fortalecimento do estado, os movimentos de ocupação desejam a criação de um espaço comum, onde a diferença possa existir. Esta estratégia política é potente ao combater jogos de verdade que afirmam que o espaço público é de ninguém, transformando-o assim em espaço compartilhado. Dessa forma, a experiência de ocupação da rua produz a atitude de tomar parte nos assuntos da cidade ao mesmo tempo em que possibilita que, aqueles que ocupam, resistam à homogeneização dos modos de viver urbanos e afirmem-se como sujeitos singulares na diferença.

\section{Sobre ocupar a cidade e ocupar-se de si: algumas reflexões e muitas perguntas}

Os modos como se articulam as ocupações do espaço público narrados até então, já identificam que os modos de produção da cidade são, também, os modos de produção dos sujeitos. A cidade de lugares de "ninguém”, produz, também, sujeitos "anônimos", que não desejam ser reconhecidos como sujeitos de uma cidade forjada na lógica do consumo e das éticas do privado. Estas articulações entre as ocupações da cidade e a ocupação de si mesmos foram trabalhadas, aqui, através da proposta foucaultiana da ética do cuidado de si, entendida como formas de inquietar-se consigo mesmo e permitir experimentar-se nas relações de estranhamento, com potência de produção da diferença e da crítica aos modos homogeneizantes de ser e de viver.

Para tanto, importante situar-nos nos chamados escritos tardios do autor, em que a temática do poder e da liberdade são ressignificadas a partir do abandono da hipótese repressiva (Ortega, 1999). A possibilidade de lidar com tais temáticas a partir da relativização da hipótese repressiva significa admitir a complexidade das relações e processos em que o poder - agora como fator produtivo e não apenas restritivo - está envolvido. Assim, poder, resistência e liberdade estabelecem relações entre si, que envolvem a violência, a dominação, as práticas de liberação e de liberdade.

O poder, conforme Foucault, é relação, onde a resistência é inerente e se dá a partir de uma relação agonística e de provocação com o poder institucionalizado, indicando a insubmissão da liberdade. As resistências segundo Foucault (1994) podem ser "de espécies diversas: possíveis, necessárias, improváveis, espontâneas, selvagens, solitárias, concertadas, rastejantes, violentas, irreconciliáveis, prontas à transação, interessadas ou sacrificiais; por definição, elas não podem existir senão no campo estratégico das relações de poder" (Foucault, 1994, p. 99). 
A partir desta perspectiva, afirma-se que existem situações de cristalização e fixação de relações de poder, criando relações dessimétricas. Neste tipo de situação a margem de liberdade é muito baixa (Foucault, 2004), já que as condições de exercício do poder não são igualitárias. Foucault chamou estas cristalizações - que são o que os movimentos sociais vêm denunciar - de "estados de dominação". Tais estados são aqueles a serem evitados e combatidos, enquanto as relações de poder são inerentes à forma como nos reconhecemos como seres humanos. Uma maneira de impedir a cristalização das relações de poder em estados de dominação é sempre colocá-las sob análise, através de um processo político que é constante. O termo “jogos de poder" mostra como os fluxos de poder e de verdades se conjugam e se arranjam, organizando os sujeitos e suas práticas, estabelecendo posições, espacialidades e legitimidades.

Na diferenciação entre a relação de violência (ou estado de dominação) e a relação de poder, Foucault (1995) afirma que o exercício do poder é menos da ordem do afrontamento entre dois adversários e mais da ordem do governo. Governar é agir sobre a ação dos outros, é uma busca por delimitar as possibilidades de ação do outro, ou seja: o exercício do poder, quando ele não se cristaliza, é o governo dos homens sobre eles mesmos (Foucault, 2011 ). Para haver poder, portanto, é preciso que haja a presunção da liberdade, visto que ela própria não existe concretamente.

Para o autor, existem as práticas de liberdade e os processos de liberação (Foucault, 2004), onde as práticas da liberdade estão ligadas à prática reflexiva, pois a reflexão é o que permite escolhas que atentam para uma divisão mais ou menos igualitária do poder. Os processos de liberação, no entanto, não são necessariamente reflexivos, mas se referem a outros tipos de fluxos. Eles surgem para dissolver estados de dominação, de maneira espontânea e por vezes violenta. Em situações de dominação intensa e cristalizada, por vezes tornam-se necessários os processos de liberação para que se crie um terreno onde seja possível a produção de práticas de liberdade. É importante manter em perspectiva, no entanto, que as práticas de liberação, mesmo que atuem na dissolução de estados de dominação, não garantem por si só a produção de sujeitos livres.

A problematização da liberdade no pensamento foucaultiano está relacionada à ética. A ética, assim, não se refere a um conjunto de normas, mas à faculdade da reflexão e da problematização. A ética formulada como ética do cuidado de si implica uma reflexão constante e cuidadosa sobre os modos como nos conduzimos na relação com o poder e com a liberdade. Esta noção foi retomada por Foucault a partir da construção filosófica grega clássica. O cuidado de si, assim, mais do que uma prática, é uma ética que nos convida à reflexão e à inquietação sobre nossa própria condição, sobre os modos como nos tornamos o que somos. Como nos tornamos escravos de certas formas de ser e de viver e que fluxos podem dar potência para práticas de liberdade que desafiem estas lógicas dominadoras. Ao criar certos estranhamentos nos modos como nos reconhecemos como sujeitos, a reflexão ética força ao pensamento de si mesmo como um outro. Nesta marca de alteridade, reconhecer a si mesmo é, também, um processo de inquietação, de movimento, de transformação. Este processo implica no ocupar-se de si mesmo como estratégia de inquietação e de estranhamento.

Este momento da reflexão foucaultiana se faz especialmente interessante na problematização dos movimentos sociais por trazer de maneira tão obstinada a temática da liberdade. $\mathrm{O}$ autor afirma que o pensamento político tradicional se refere ao sujeito de direitos e não ao sujeito ético. Recolocar a questão política a partir da ética parece coincidir com uma análise do poder que admite aos sujeitos mais possibilidades de ação, ao dotá-lo - de 
maneira radical - de uma intensa capacidade de agência sobre aquilo que experiencia social e subjetivamente. Mais do que um saber, se trata de construir uma habilidade de suportar o não-saber, pois traz a ideia de que a "sabedoria" talvez se relacione mais com a habilidade de perguntar do que com a capacidade de responder através de conhecimentos cumulativos e independentes do viver.

Ocupar-se de si, portanto, pode estar articulado aos modos de ocupação da cidade e da vida. Pode-se pensar em que medida os movimentos sociais que têm na ocupação dos espaços públicos sua principal estratégia de luta, abrem espaço para ocupar-se de si mesmos. Ocupar-se como sujeitos que se afirmam em processos que produzem práticas de liberdade e ocupar-se como movimento social que se ocupa da sua própria condição. Nestes casos, a inquietação e a problematização da liberdade e do poder podem criar práticas reflexivas, sempre precárias, sempre provisórias, mas que indicam problematizações éticas. Ao colocar em análise os modos de viver, tanto quanto as relações com o espaço ou a política, abrem-se outros fluxos, onde a vida e os movimentos podem compor vidas em movimento.

\section{Referências}

Alves, G. A. (2011). A requalificação do centro de São Paulo. Estudos Avançados, 25(71), 109-1 18. Alves, G. (2012). Ocupar Wall Street... e depois? In Occupy: movimentos de protesto que tomaram as ruas. São Paulo: Boitempo Editorial.

Baremblitt, G. F. (1996). Compêndio de Análise Institucional. Rio de Janeiro: Rosa dos Tempos. Barros, L. P. \& Kastrup, V. (2012). Cartografar é acompanhar processos. In E. Passos, V. Kastrup, \& L. Escossia (Orgs.), Pistas dos método da cartografia: Pesquisa-intervenção e produção de subjetividade (pp. 52-75). Por to Alegre: Sulina.

Constituição Federativa. (1988). Constituição da República Federativa do Brasil. São Paulo: Atlas, 2000. Recuperado de http://www.planalto.gov.br/ccivil_03/constituicao/constituicao.htm

Caldeira, H. B. R. (1997). Enclaves Fortificados: a nova segregação urbana. Novos Estudos CEBRAP, 47, 155-176.

Castells, M. (2013) Redes de Indignação e Esperança: Movimentos Sociais na Era da Internet. Rio de Janeiro: Zahar.

Deleuze, G. \& Guattari, F. (1992). O que é a Filosofia? São Paulo: Editora 34

Deleuze, G. \& Guattari, F. (1995). Mil Platôs - Capitalismo e Esquizofrenia, Vol. 1. Rio de Janeiro: Ed. 34.

Foucault, M. (1994). A História da Sexualidade: a vontade de saber, V. 1. Lisboa: Relógio d'água.

Foucault, M. (1995). O Sujeito e o Poder. In H. Dreyfus \& P. Rabinow (Orgs.), Michel Foucault: Uma Trajetória Filosófica para além do estruturalismo e de hermenêutica (pp. 231-249). Rio de Janeiro: Forense Universitária.

Foucault, M. (2004). A Ética do Cuidado de Si como Prática da Liberdade. In Ditos e Escritos: Ética, Sexualidade, Política. v. 5, (pp. 264-287). Rio de Janeiro: Forense Universitária

Foucault, M. (2011). O Governo de si e dos outros. São Paulo: Martins Fontes. 
Foucault, M. (2012). A Coragem da Verdade. São Paulo: Martins Fontes.

Gallo, I. C. D. (2008). Punk: Cultura e Arte. Varia História, 24(40), 747-770.

Harvey, D. (2012). Os rebeldes na rua: o partido de Wall Street encontra sua Nêmesis. In Occupy: movimentos de protesto que tomaram as ruas. São Paulo: Boitempo Editorial, 2012.

Hardt, M. \& Negri, A. (2004). Multidão: Guerra e democracia na era do Império. Rio de Janeiro: Record.

Hess, R. \& Weigand, G. (2006). A escrita implicada. Revista Reflexões e Debates, 11, 14-25

Joffe, G. (2011) A Primavera Árabe no Norte de África: origens e perspectivas de futuro. Relações Internacionais, 30, 85-116

Konzen, L. P. (2010). Espaços público urbanos e pluralismo jurídico: dos bens de uso comum do povo aos direitos à cidade. Dissertação de Mestrado, Programa de Pós-graduação em Direito, Universidade Federal de Santa Catarina, Florianópolis, SC.

Lazzarotto, G. D. R. (2009). Pragmática de uma língua menor: um diário coletivo e políticas públicas juvenis. Tese de Doutorado, Programa de Pós-graduação em Educação, Universidade Federal do Rio Grande do Sul, Porto Alegre, RS.

Lefebvre, H. (2000). La production de l'espace (4. ed.). Paris: Anthropos.

Mizoguchi, D. H. (2009). Segmentaricidades: passagens do Leme ao Pontal. São Paulo: Plêiade.

Narciso, C. A. F. (2009). Espaço público: acção politica e práticas de apropriação: Conceito e procedências. Estudos e Pesquisas em Psicologia, 9(2), 265-291.

Ortega, F. (1999). Amizade e estética da existência em Foucault. Rio de Janeiro: Edições Graal.

Safatle, V. (2012). Amar uma ideia. In Occupy: movimentos de protesto que tomaram as ruas. São Paulo: Boitempo Editorial.

Varella, M. D. (1998). MST, um movimento social? In D. S. Silveira \& F. S. Xavier (Orgs.), O Direito Agrário em debate (pp. 152-160). Porto Alegre: Livraria do Advogado.

Zizek, S. (2012). O Ano em que sonhamos perigosamente. São Paulo: Boitempo Editorial. 


\section{JAQUELINE TITTONI \\ https://orcid.org/0000-0002-3450-080X}

Mestre em Sociologia pela Universidade Federal do Rio Grande do Sul (1992) e doutorado em Sociologia pela Universidade Federal do Rio Grande do Sul (1999). Realizou estágio de pós-doutorado no master em Psicologia Social da Universidade Autónoma de Barcelona (2005-2006). Atualmente é professora adjunto da Universidade Federal do Rio Grande do Sul, Porto Alegre/RS.

Endereço: Rua Ramiro Barcelos 2600. Bairro Santa Cecília. Porto Alegre RS, CEP 90035 - 003.

E-mail: jatittoni@gmail.com

\section{LÚCIA KARAM TIETBOEHL}

https://orcid.org/O000-0002-5811-5623

Psicóloga, licenciada em psicologia e mestre em Psicologia Social e Institucional pela Universidade Federal do Rio Grande do Sul.

E-mail: luciakt@gmail.com

\begin{tabular}{|l|l|}
\hline \multirow{3}{*}{ Histórico } & Submissão: 12/07/2017 \\
& Revisão: 25/10/2019 \\
& Aceite: 09/12/2019 \\
\hline \multirow{3}{*}{ Contribuição } & Concepção: L.K.T., J.T. \\
& Coleta de dadlos: L.K.T. \\
& Análise de dados: L.K.T., J.T. \\
& Elaboração do manuscrito: L.K.T., J.T. \\
& Revisões de conteúdo intelectual importante: J.T., L.K.T. \\
& Aprovação final do manuscrito: L.K.T., J.T. \\
\hline \multirow{2}{*}{ Financiamento } & Edital CAPES Demanda Social \\
& Processo 1189324 \\
\hline
\end{tabular}

